\title{
Cyclooxygenase- 2 expression is induced by celecoxib treatment in lung cancer cells and is transferred to neighbor cells via exosomes
}

\author{
JAYOUNG KIM ${ }^{1}$, SEUNG-WOO HONG ${ }^{1}$, SEONGHAN KIM ${ }^{1}$, DAEJIN KIM ${ }^{1}$, DAE YOUNG HUR ${ }^{1}$, \\ DONG-HOON JIN ${ }^{2}$, BOMI KIM ${ }^{3}$ and YEONG SEOK KIM ${ }^{1}$
}

${ }^{1}$ Department of Anatomy and Research Center for Tumor Immunology, College of Medicine, Inje University, Busan 47392;
${ }^{2}$ Department of Convergence Medicine, Asan Medical Center, University of Ulsan College of Medicine, Seoul 05505;
${ }^{3}$ Department of Pathology, Haeundae Paik Hospital, College of Medicine, Inje University, Busan 48108, Republic of Korea

Received September 5, 2017; Accepted December 8, 2017

DOI: $10.3892 /$ ijo.2017.4227

\begin{abstract}
Lung cancer is one of most common types of cancer worldwide. Lung cancer results in a death higher rate each year compared to colon, breast and prostate cancer combined. Celecoxib is a selective inhibitor of cyclooxygenase-2 (COX-2), an enzyme of which the expression is induced by various stimuli, such as inflammation. In addition, celecoxib triggers COX-2 loading on exosomes. Exosomes are small vesicles composed of a lipid bilayer membrane and are found in most biological fluids, such as blood breast milk and urine. In this study, we focused on exosomes containing COX-2 proteins from lung cancer cells to determine their involvement in the interaction with neighbor cells following treatment with celecoxib. We found that celecoxib induced COX-2 expression in both the cytosol and exosomes in lung cancer cells. Exosomes from celecoxib-treated lung cancer cell culture supernatant were isolated and incubated with several types of cells. The THP-1, monocytic leukemia cell line effectively absorbed COX-2 by lung cancer cell-derived exosomes. Following incubation with exosomes, the COX-2 protein level was increased in the THP-1 cells; however, COX-2 mRNA expression was not affected. Moreover, prostaglandin $\mathrm{E}_{2}\left(\mathrm{PGE}_{2}\right)$ and vascular endothelial growth factor (VEGF) production by THP-1 cells was increased following incubation with exosomes from celecoxib-treated lung cancer cells. Conditioned medium from THP-1 following incubation with exosomes promoted formation in EA.hy926 cells. Taken together, our findings suggest
\end{abstract}

Correspondence to: Dr Yeong Seok Kim, Department of Anatomy and Research Center for Tumor Immunology, College of Medicine, Inje University, 75 Bokji-ro, Busanjin-gu, Busan 47392, Republic of Korea

E-mail: newsoft@inje.ac.kr

Abbreviations: COX-2, cyclooxygenase-2; PG, prostaglandin; EGFR, epidermal growth factor receptor

Key words: exosome, celecoxib, cyclooxygenase-2, lung cancer, intercellular interaction that celecoxib induces COX-2 expression in lung cancer cells, and that highly expressed COX-2 in exosomes can be transferred to other cells.

\section{Introduction}

Lung cancer is the leading cause of cancer-related mortality worldwide, with a higher rate of mortality each year compared with colon, breast and prostate cancers (1-4). Targeted therapy has been used for the clinical treatment of lung cancer and therapies targeting epidermal growth factor receptor (EGFR) or vascular endothelial growth factor (VEGF) have been shown to be effective, as well as traditional chemotherapy (5-8). Cyclooxygenase (COX), an essential enzyme in prostaglandin (PG) synthesis, represents another potential target. PGs are involved in various physiological and pathogenic processes, such as inflammatory reactions, gastro-intestinal cytoprotection, and ulceration, hemostasis and thrombosis (9-15). The COX enzyme has two isoforms, COX-1 and COX-2. COX-1 is constitutively expressed in most cells and tissues, and produces PGs involved in the maintenance of the gastric mucosa, the regulation of renal blood flow and platelet aggregation. By contrast, COX-2 can be induced by various pro-inflammatory and mitogenic stimuli (9-11).

The inhibition of COX-1 causes side-effects, such as gastrointestinal tract bleeding and kidney failure (13,16-18). By contrast, COX-2 inhibitors are widely used as they have few side-effects. Celecoxib, a COX-2 inhibitor, induces cell cycle arrest, inhibits tumor growth, suppresses tumor angiogenesis and induces apoptosis in several types of cancer. Such responses to celecoxib have been investigated in cells that highly express COX-2 $(15,18,19)$. However, Ramer et al reported that the expression of COX-2 was paradoxically increased by celecoxib, which activated peroxisome proliferator-activated receptor (PPAR) $\gamma$ (20). The increased COX-2 expression induced by celecoxib may modulate local inflammatory responses and COX-2 may thus be a potential target of sustained celecoxib treatment.

Exosomes, small vesicles composed of a lipid bilayer membrane, are found in most biological fluids (21-23). Several characteristics of exosomes have been explored, including their small size (50-100 nm), cup-shaped morphology and 
specific protein markers (24-27). The major role of exosomes is the delivery of bioactive molecules between cells $(21,28)$. Recently, exosomes have been tested in the treatment of cancers. Cancer-derived exosomes can be used as biomarkers for cancer diagnosis as they are enriched with proteins, mRNAs and miRNAs related to cancer $(21,24,25,28)$. Of note, in this study, we found that celecoxib increased COX-2 expression in both the cytoplasm and exosomes in lung cancer cells.

In the present study, we investigated whether adjacent cells may acquire exosomes containing COX-2 from lung cancer cells following treatment with celecoxib, focusing on the intercellular responses of cells neighboring lung cancers related to exosome transport.

\section{Materials and methods}

Cell culture and celecoxib treatment. The human lung cancer carcinoma cell lines, A549, H460 and 11-18, the human monocytic cell line, THP-1, the Burkitt's lymphoma B cell line, Raji, human primary umbilical vein endothelial cells (HUVECs) and the human umbilical vein cell line, EA.hy926, were all purchased from the American Type Culture Collection (ATCC, Manassas, VA, USA). All the cells, apart from the HUVECs and EA.hy926 cells were maintained in RPMI-1640 medium (HyClone, Logan, UT, USA). The HUVECs were maintained with F-12K medium containing endothelial growth factors and the EA.hy926 cells was maintained in DMEM supplemented with $10 \%$ fetal bovine serum (FBS), with $100 \mathrm{U} / \mathrm{ml}$ penicillin and $100 \mu \mathrm{g} / \mathrm{ml}$ streptomycin (all from HyClone) at $37^{\circ} \mathrm{C}$ in a humidified $5 \% \mathrm{CO}_{2}$ atmosphere.

To determine the optimal concentration, the cells were incubated with celecoxib (cat. no. C251000; Toronto Research Chemicals, Toronto, ON, Canada) at $0,25,50,75$ or $100 \mu \mathrm{M}$ for $16 \mathrm{~h}$, and $75 \mu \mathrm{M}$ for $0,2,4,6,8$ or $12 \mathrm{~h}$. To perform further experiment with minimally affected cell growth inhibition, $75 \mu \mathrm{M}$ of celecoxib was treated in lung cancer cells for $16 \mathrm{~h}$.

Monocyte preparation. Peripheral blood mononuclear cells (PBMCs) from human blood were isolated by Ficoll-Paque (Amersham Life Science, Buckinghamshire, England) density-gradient centrifugation. Monocyte purification was achieved using a monocyte isolation kit (Miltenyi Biothec, Bergisch Gladhach, Germany). PBMCs were combined with FcR blocking reagent and biotin-antibody cocktail and incubated for $10 \mathrm{~min}$ at $4^{\circ} \mathrm{C}$. Subsequenlty, anti-biotin MicroBeads were added and incubated for $15 \mathrm{~min}$ at $4^{\circ} \mathrm{C}$. The cells were centrifuged at $300 \times \mathrm{g}, 4^{\circ} \mathrm{C}$ for $10 \mathrm{~min}$ after washing and resuspended with buffer. The cell suspension was loaded into columns and rinsed with buffer. The cells that passed through were unlabeled cells, representing the enriched monocyte fraction. This study was approved by the Institutional Bioethics Review Board at the College of Medicine, Inje University, Busan, Korea and all donors provided informed consent for the use of their samples in this study.

Analysis of cytotoxicity. Cell viability was examined by WST-1 assay (Takara, Shiga, Japan). The cells were seeded in 96 -well plates $\left(5 \times 10^{3}\right.$ cells/well) and incubated for $24 \mathrm{~h}$. The cells were treated with various concentrations of exosomes overnight. WST-1 then was added to each well, and the plates were incubated for $1 \mathrm{~h}$ and the absorbance was measured using a microplate reader (Multiskan FC model; Thermo Scientific, Waltham, MA, USA) at a wavelength of $450 \mathrm{~nm}$.

$R T-P C R$. Total RNA was isolated using TRIzol reagent (Invitrogen, Carlsbad, CA, USA) according to the manufacturer's instructions. Briefly, the harvested cells were mixed with TRIzol reagent and chloroform. The mixture was centrifuged at $12,000 \mathrm{x} \mathrm{g}$ for $15 \mathrm{~min}$ at $4^{\circ} \mathrm{C}$. The supernatant was discarded and washed with $75 \%$ ethanol in DEPC-treated water. The pellet containing RNA was resuspended with DEPC-treated water. RT-premix (Bioneer, Daejeon, Korea) was used for cDNA synthesis from $2 \mu \mathrm{g}$ of total RNA. The mixture of RNA and oligo(dTs) was combined with RT-premix and incubated for $1 \mathrm{~h}$ at $42^{\circ} \mathrm{C}$ and $5 \mathrm{~min}$ at $95^{\circ} \mathrm{C}$. cDNA was amplified using primers the following primers: COX-2 forward, GCT CCT ACC CAC GCA GAT TT and reverse, AGA CGC CAT TTG GAT TGG GT; and $\beta$-actin forward, ATC CAC GAA ACT ACC TTC AA and reverse, ATC CAC ACG GAG TAC TTG C and Tenuto PCR premix (Enzynomics, Daejeon, Korea) in a PCR Thermal Cycler (Takara). PCR products were analyzed by gel electrophoresis in TAE buffer through $1 \%$ agarose gels. The densities of bands were analyzed using ImageJ $1.51 \mathrm{~K}$ software [National Institutes of Health (NIH), Bethesda, MD, USA].

Western blot analysis. The cells were harvested, rinsed with phosphate-buffered saline (PBS) (Welgene, Gyeongsan, Korea) and lysed in lysis buffer (Invitrogen) supplemented with protease inhibitor cocktail (Sigma, St. Louis, MO, USA). The cells were incubated on ice for $10 \mathrm{~min}$ and centrifuged for $10 \mathrm{~min}$ at $15,000 \mathrm{x}$ g. Protein quantity was determined by BCA assay (Thermo Scientific) and then separated on $10 \%$ sodium dodecyl sulfate (SDS)-polyacrylamide gels overlaid with a $4 \%$ polyacrylamide stacking gel. The proteins were transferred onto a nitrocellulose membrane after separation. The membranes were blocked with $5 \%$ skim milk for $1 \mathrm{~h}$ at room temperature and washed 3 times with Tris-buffered saline containing $0.1 \%$ Tween-20 (TBST, pH 7.4) for $10 \mathrm{~min}$ each. Each membrane was incubated with primary antibodies to COX-2 (1:1,000 dilution, cat. no. sc-12282; Cell Signaling Technology, Beverly, MA, USA), CD63 (1:500 dilution, cat. no. sc-15363) or $\beta$-actin (1:2,000 dilution, cat. no. sc-47778) (both from Santa Cruz Biotechnology, Inc., Santa Cruz, CA, USA) in $0.1 \% \mathrm{TBST}$ at $4^{\circ} \mathrm{C}$ overnight. The membranes were then washed with $0.1 \%$ TBST 3 times for $10 \mathrm{~min}$ and incubated with secondary antibody [anti-rabbit IgG [1:5,000 dilution, cat. no. 7074; Cell Signaling Technology) for COX-2 and CD63; anti-mouse IgG (1:5,000 dilution, cat. no. 7076; Cell Signaling Technology) for $\beta$-actin] for $1 \mathrm{~h}$ at room temperature. Following incubation, each membrane was washed with $0.1 \%$ TBST 3 times. $\beta$-actin or CD63 was detected as an internal standard or exosome marker, respectively. Signals were detected by chemiluminescence (Fuji Photo Film Co., Tokyo, Japan). The densities of the bands were analyzed using Image J $1.51 \mathrm{~K}$ software (NIH).

Isolation of exosomes and culture with exosomes. Exosomes were isolated using an Exo-spin exosome purification kit 
(Cell Guidance Systems, St. Louis, MO, USA) according to the manufacturer's instructions. The H460 and 11-18 cells were cultured in $150-\mathrm{mm}$ dishes and cell culture supernatant was collected by centrifugation at $300 \mathrm{x}$ g for $10 \mathrm{~min}$. The supernatant was transferred into new tubes and centrifuged at $20,000 \mathrm{x} \mathrm{g}$ at $4^{\circ} \mathrm{C}$ for $30 \mathrm{~min}$ in a high-speed centrifuge. The collected supernatant was transferred into new tubes and buffer A (provided with the kit) was added. The mixture was incubated at $4^{\circ} \mathrm{C}$ for overnight after mixing well. The following day, the mixture was centrifuged at $20,000 \times \mathrm{g}$ at $4^{\circ} \mathrm{C}$ for $1 \mathrm{~h}$. Exosome-containing pellets were resuspended with $\mathrm{PBS}$ following the aspiration of the supernatant. Spin columns were prepared and spun down at $50 \mathrm{x}$ g for $30 \mathrm{sec}$. Pellets containing exosomes were loaded into the tops of columns and centrifuged at $50 \mathrm{x}$ g for $60 \mathrm{sec}$. The columns were placed into 1.5-ml tube and rinsed with PBS or medium applied at the top and centrifuged at $50 \mathrm{x}$ g for $60 \mathrm{sec}$.

The purified exosomes were used to examine cell viability, the transport of COX-2, and the production of cytokines in cells uptaking exosomes. To examine cell viability, various concentration $(100,250$ or $500 \mu \mathrm{g} / \mathrm{ml})$ of exosomes were incubated with the THP-1 cells for $24 \mathrm{~h}$. For the measurements of the COX-2 concentration and the production of cytokines, exosomes (75 or $150 \mu \mathrm{g} / \mathrm{ml}$ ) were used to treat the THP-1, human primary monocytes, HUVECs, EA.hy926 or Raji cells for $16 \mathrm{~h}$.

Transmission electron microscopy. Exosomes were purified using an Exo-spin kit and resuspended in a small volume of PBS. Exosomes were fixed with $2.5 \%$ glutaraldehyde solution, washed and post-fixed in $1 \%$ osmium tetroxide. The pellets were then dehydrated through an ethanol series followed by acetone, and then embedded in epoxy resin. Ultrathin sections were contrasted with uranyl acetate and lead citrate. Transmission electron microscopy JEM-1200 EX II (Jeol, Tokyo, Japan) was used to view these sections at $80 \mathrm{kV}$.

Enzyme immunoassay (EIA) and enzyme-linked immunosorbent assay (ELISA). To measure the concentrations of $\mathrm{PGE}_{2}$ and VEGF, cell culture supernatants were examined using an EIA kit (Cayman Chemical Co., Ann Arbor, MI, USA) and an ELISA kit (R\&D Systems, Minneapolis, MN, USA) according to the instructions provided by the respective manufacturers. The kit contains the required solutions and all antibodies, and concentrations and dilution ratios followed the instructions. Briefly, $\mathrm{PGE}_{2}$ standard solution and culture supernatants were added to plates with goat polyclonal anti-mouse IgG. $\mathrm{PGE}_{2} \mathrm{AChE}$ tracer and $\mathrm{PGE}_{2}$ monoclonal antibodies (provided with the kit) were added followed by incubation for $18 \mathrm{~h}$ at $4^{\circ} \mathrm{C}$. Ellman's reagent (provided with the kit) was added to the wells after rinsing 5 times with washing buffer and the plates were incubated for $1 \mathrm{~h}$. The absorbance was measured with a microplate reader (Multiskan FC model, Thermo Scientific) at $405 \mathrm{~nm}$.

To coat the plates, VEGF capture antibody (provided with the kit) was added to the wells followed by incubation overnight. Each plate was then washed and blocked for $1 \mathrm{~h}$. Standard solutions and culture supernatants were added after washing. VEGF detection antibody (provided with the kit) was then added followed by incubation for $2 \mathrm{~h}$, followed by the addition of streptavidin-HRP and incubation for $20 \mathrm{~min}$ in indirect light and washing of each plate three times. Substrate solu- tions were added followed by incubation for $20 \mathrm{~min}$ in indirect light. Stop solution was added and the optical density of each well was determined using a microplate reader (Multiskan FC model; Thermo Scientific) set to $450 \mathrm{~nm}$.

Tube formation assay. Tube formation assay was conducted in 96-well plates coated with $50 \mu \mathrm{l}$ of growth factor-reduced Matrigel (BD Biosciences, San Jose, CA, USA) according to the manufacturer's instructions. The EA.hy926 cells $\left(1.0 \times 10^{4}\right.$ cells/well) were treated with filtered THP-1 supernatant (following incubation with exosomes carrying high concentrations of COX-2) or control medium for an additional $16 \mathrm{~h}$. Tube formation was photographed under a microscope (iRIS; Logos Biosystems, Anyang, Korea). The numbers of tubes in an identical area were manually counted and statistically analyzed using the Student's t-test. A P-value $<0.05$ was considered to indicate a statistically significant difference.

Statistical analysis. The densities of all the bands were measured using Image $1.51 \mathrm{~K}$ software $(\mathrm{NIH})$, and the relative ratio to the internal standard was calculated. Two-sided Student's t-tests were used to evaluate differences between 2 groups. For comparison of viabilities between more than 2 groups, data were analyzed using one-way ANOVA (with Tukey's multiple comparison test). The data from ELISA and tube formation data are presented as the means \pm SD. A $\mathrm{P}$-value $<0.05$ was considered to indicate a statistically significant difference.

\section{Results}

Celecoxib paradoxically increases $C O X-2$ expression in lung cancer. Cytotoxicity was examined when the lung cancer cell lines were treated with celecoxib. The A549, H460 and 11-18 lung cancer cell lines were incubated with various concentrations of celecoxib. The concentration of celecoxib leading to the $50 \%$ suppression of cell viability was estimated to be $\sim 50 \mu \mathrm{M}$ in the $\mathrm{H} 460$ and $11-18$ cells, but $>100 \mu \mathrm{M}$ in the A549 cells. We observed that higher concentrations of celecoxib led to a greater decrease in the viability of the lung cancer cells (data not shown).

To observe the effects of celecoxib on COX-2 expression in lung cancer cells following treatment with celecoxib at various concentrations and treatment durations, the 3 lung cancer cell lines, A549, H460 and 11-18, were treated with 25, 50, 75 or $100 \mu \mathrm{M}$ of celecoxib for $6 \mathrm{~h}$. COX-2 expression was then detected by western blot analysis. The expression of COX-2 was elevated in a dose-dependent manner (Fig. 1A), as well as in a time-dependent manner when the cells lines were treated with $75 \mu \mathrm{M}$ of celecoxib for $2,4,6,8$ or $12 \mathrm{~h}$. A marked increase in COX-2 expression was observed after $4 \mathrm{~h}$ (Fig. 1B). COX-2 mRNA expression was immediately increased following treatment with celecoxib (Fig. 1C).

Celecoxib increases COX-2 expression in both the cytoplasm and exosomes. The $\mathrm{H} 460$ cells were cultured in medium supplemented with exosome-free FBS, and exosomes were then isolated. Transmission electron microscopy revealed that purified exosomes were $\sim 100 \mathrm{~nm}$ in size and had a dish-like shape (Fig. 2A). 
A

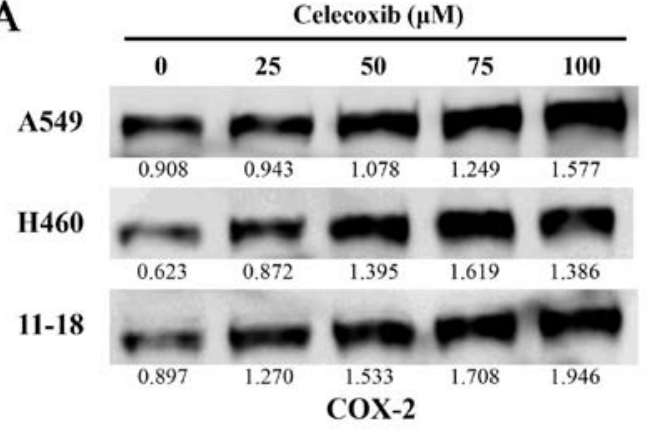

B

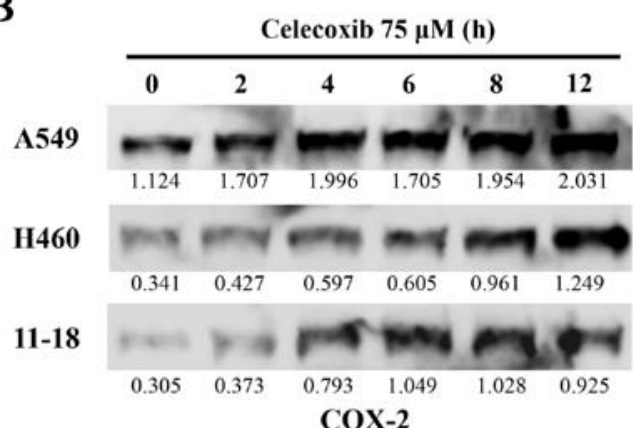

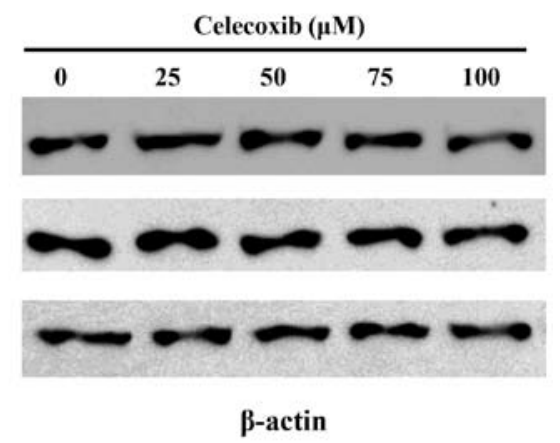

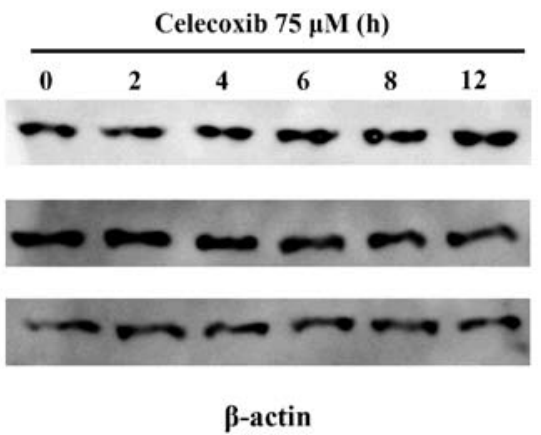

C

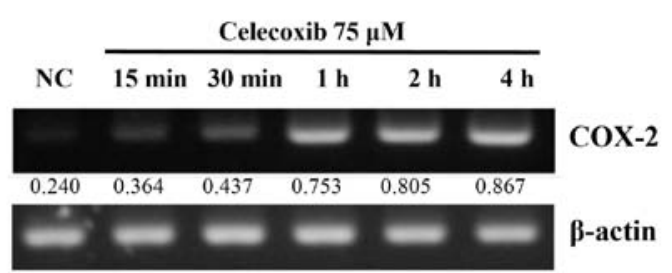

Figure 1. Cell viability and cyclooxygenase-2 (COX-2) expression following the treatment of lung cancer cell lines with celecoxib. (A) The lung cancer cell lines, A549, H460 and 11-18, were treated with celecoxib $(0,25,50,75$ and $100 \mu \mathrm{M})$ for $16 \mathrm{~h}$. (B) The A549, H460 and 11-18 cells were also treated with celecoxib at $75 \mu \mathrm{M}$ for $0,2,4,6,8$ and $12 \mathrm{~h}$. The cells were then harvested and proteins were extracted. (A and B) COX-2 protein expression was measured by western blot analysis. A representative example of 5 independent experiments is shown. (C) COX-2 mRNA expression at the indicated time points was detected by RT-PCR. The numbers under the bands indicate the ratio between densities of marked bands and $\beta$-actin. A representative example of 3 independent experiments is shown.

The H460 and 11-18 cells were incubated in exosome-free FBS with $75 \mu \mathrm{M}$ of celecoxib for $16 \mathrm{~h}$, and cell lysates and exosomes were then prepared from cells and supernatants, respectively. The expression level of COX-2 was detected by western blot analysis. COX-2 expression was increased in the cell lysates and exosomes collected from the celecoxib-treated cells compared to the control cells. The concentration of COX-2 in exosomes from the 11-18 cells was much higher than that from the H460 cells. CD63 was used as an exosome marker and $\beta$-actin was used as internal standard for cell lysates (Fig. 2B).

COX-2 protein is transferred to THP-1 cells through exosomes from celecoxib-treated lung cancer cells. Exosomes were isolated from celecoxib-treated and untreated 11-18 cells. Cell viability was determined using the monocytic leukemia cell line, THP-1, to confirm that there was no change in the cell response by substances derived from other cells. The THP-1 cells were seeded on 96-well plates and then 100, 250 and $500 \mu \mathrm{g} / \mathrm{ml}$ of exosomes were added. WST-1 was added following incubation for $24 \mathrm{~h}$ and detected using a microplate reader. In all wells, the suppression of cell viability was not observed following treatment with exosomes from the control and celecoxib-treated cells ( $\mathrm{P}>0.05)$ (Fig. 3A).
As a small quantity of celecoxib carried in exosomes can directly affect THP-1 cells, the THP-1 cells were treated with celecoxib at concentrations of $0.05,0.5,5$ and $50 \mu \mathrm{M}$ for $16 \mathrm{~h}$ and the concentration of COX-2 was detected by western blot analysis (Fig. 3B). Direct incubation with celecoxib did not increase COX-2 protein expression in THP-1 cells.

To determine whether exosomes can transfer COX-2 to other cells, exosomes isolated from the supernatant of the 11-18 cells were added to THP-1 cells at 75 and $150 \mu \mathrm{g} / \mathrm{ml}$. Following incubation with exosomes, RNA was extracted from the THP-1 cells and RT-PCR was performed. The same mRNA expression level of COX-2 was observed in all samples (Fig. 3C). However, different protein levels of COX-2 were observed, as shown by western blot analysis. COX-2 expression was higher in the cells treated with exosomes from the celecoxib-treated 11-18 cell supernatant. A greater concentration of COX-2 was detected in the cells treated with $150 \mu \mathrm{g} / \mathrm{ml}$ of exosomes than in those treated with $75 \mu \mathrm{g} / \mathrm{ml}$ (Fig. 3D). Thus, COX-2 protein appeared to have been transferred to the THP-1 cells. Exosomes did not transfer COX-2 mRNA, and did not stimulate the THP-1 cells.

COX-2 in exosomes is transferred to other cell types, as well as THP-1. To determine whether COX-2 concentration can be 
A

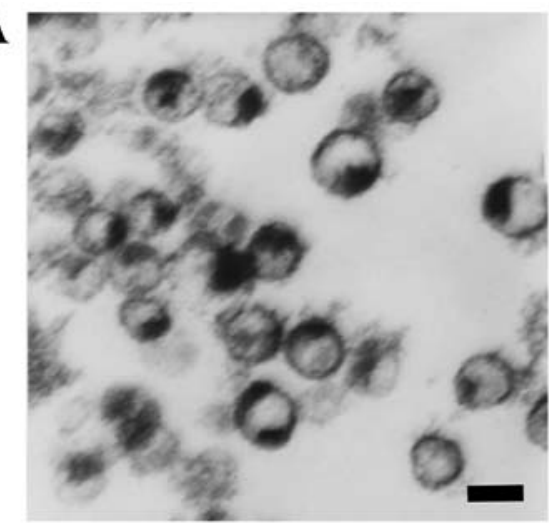

B

Lysate

Exosome

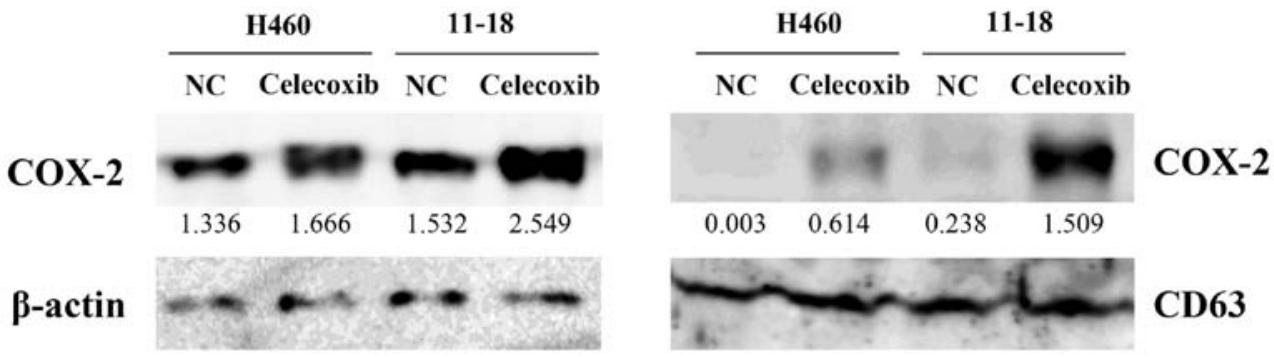

Figure 2. Purified exosomes and cyclooxygenase-2 (COX-2) expression in exosomes following treatment with celecoxib. Exosomes were purified from culture supernatants and enriched using an Exo-spin exosome purification kit. (A) Exosome pellets were processed for transmission electron microscopy and observed as magnified by $\mathrm{x} 100 \mathrm{~K}$ (scale bar, $100 \mathrm{~nm}$ ). (B) $\mathrm{H} 460$ and 11-18 cells were treated with $75 \mu \mathrm{M}$ of celecoxib for $16 \mathrm{~h}$. Exosomes were enriched using an Exo-spin exosome purification kit. COX-2 protein expression levels in cell lysates or exosomes were measured by western blot analysis. CD63 is a specific marker of exosomes. The numbers under the bands indicate the ratio between densities of marked bands and $\beta$-actin or CD63. A representative example of 4 independent experiments is shown.

A

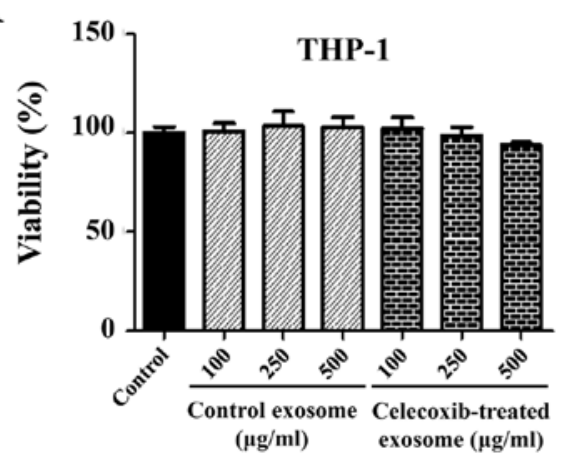

C

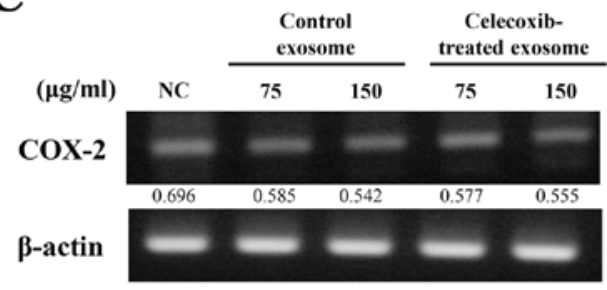

THP-1
B

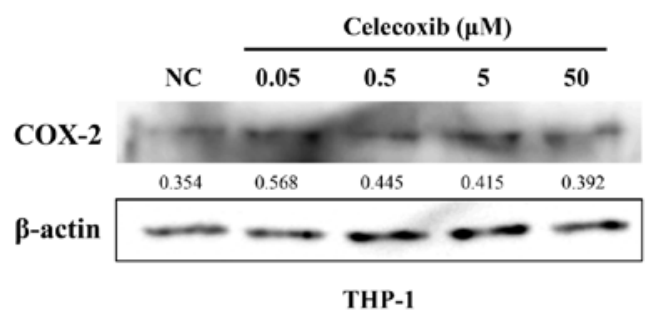

D

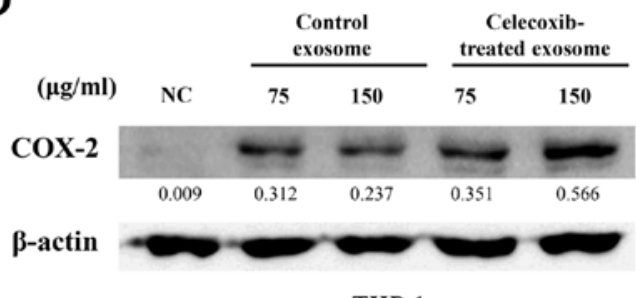

THP-1

Figure 3. cyclooxygenase-2 (COX-2) protein is transferred to THP-1 through exosomes. The 11-18 cells were treated with $75 \mu \mathrm{M}$ of celecoxib for $16 \mathrm{~h}$ and then exosomes were purified. (A) THP-1 cells were incubated with exosomes at 100, 250 and $500 \mu \mathrm{g} / \mathrm{ml}$ for $24 \mathrm{~h}$. Cell viability was measured using a WST-1 assay. (B) THP-1 cells were treated with celecoxib $(0,0.05,0.5,5$ and $50 \mu \mathrm{M})$ for $16 \mathrm{~h}$. Protein expression levels were measured by western blot analysis. A representative example of 3 independent experiments is shown. (C and D) The 11-18 cells were treated with $75 \mu \mathrm{M}$ of celecoxib for $16 \mathrm{~h}$ and then exosomes were purified. Purified exosomes were added to the THP-1 cells (75 and $150 \mu \mathrm{g} / \mathrm{ml})$. Following incubation for $16 \mathrm{~h}, \mathrm{COX}-2 \mathrm{mRNA}$ and protein expression levels in the THP-1 cells were measured by (C) RT-PCR and (D) western blot analysis, respectively. The numbers under the bands indicate the ratio between densities of marked bands and $\beta$-actin. A representative example of 4 independent experiments is shown. 
A

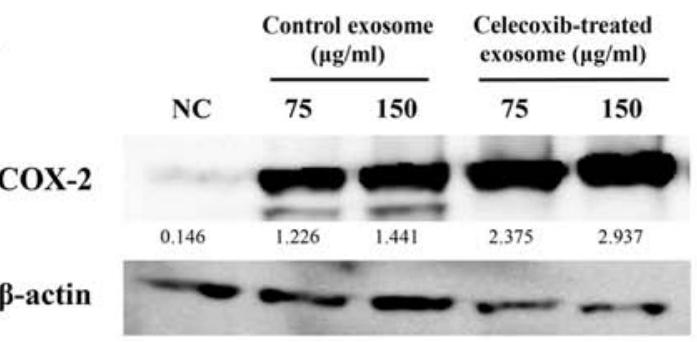

Primary monocytes

B

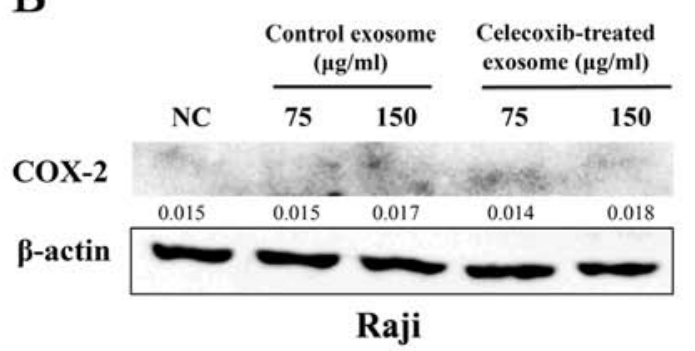

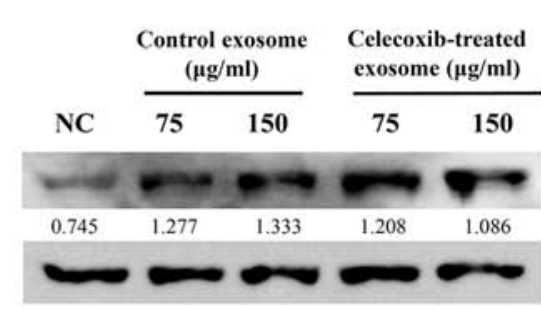

EA.hy926

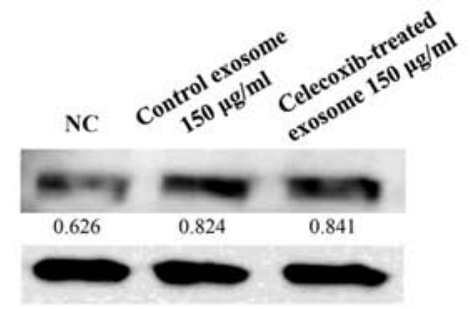

HUVEC

Figure 4. Exosomal transport of cyclooxygenase-2 (COX-2) in several types of cells. The 11-18 cells were treated with $75 \mu \mathrm{M}$ celecoxib for $16 \mathrm{~h}$ and then exosomes were purified. (A) Exosomes were added to human monocytes purified using a MACS monocyte purification kit (Miltenyi). Following incubation for $16 \mathrm{~h}, \mathrm{COX}-2$ protein expression was measured in the monocytes by western blot analysis. (B) Exosomes were added to the Burkitt's lymphoma B cell line, Raji, the human umbilical cell line, EA.hy926, and the primary endothelial cell line, HUVECs. Following incubation for $16 \mathrm{~h}$, COX-2 protein expression levels were measured by western blot analysis. The numbers under the bands indicate the ratio between densities of marked bands and $\beta$-actin. A representative example of 6 independent experiments is shown.

A

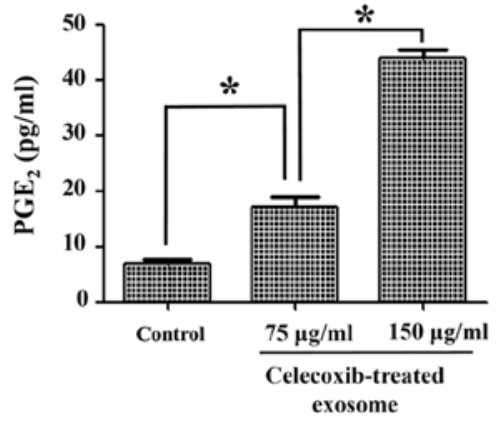

THP-1 supernatant

B
11-18

Exosomes
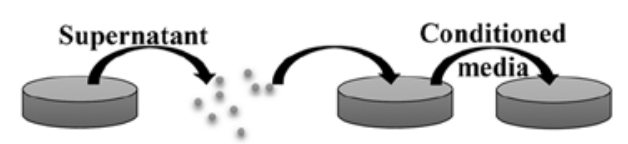

THP-1

EA.hy926
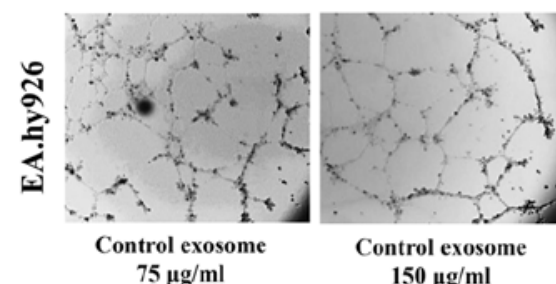

Control exosome

$150 \mu \mathrm{g} / \mathrm{m}$

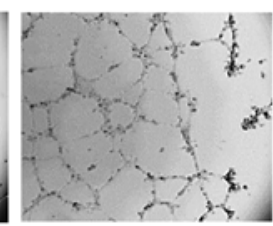

Celecoxib-treated

exosome $75 \mu \mathrm{g} / \mathrm{ml}$

Conditioned media / THP-1

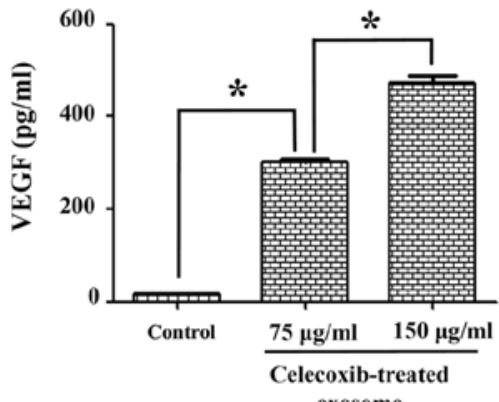

exosome

Figure 5. Prostaglandin $\mathrm{E}_{2}\left(\mathrm{PGE}_{2}\right)$, vascular endothelial growth factor (VEGF) levels and the function of VEGF in THP-1 cells following incubation with exosomes. The 11-18 cells were treated with $75 \mu \mathrm{M}$ of celecoxib for $16 \mathrm{~h}$ and then exosomes were purified. Purified exosomes were added to the THP-1 cells (75 $\mu \mathrm{g} / \mathrm{ml}$ and $150 \mu \mathrm{g} / \mathrm{ml}$ ). (A) Following incubation for $16 \mathrm{~h}$, the PGE 2 levels in the THP-1 cell culture supernatants were measured by EIA and VEGF levels were measured by enzyme-linked immunosorbent assay (ELISA). Increases in the concentrations between the 2 groups were analyzed using a Student's t-test $\left({ }^{*} \mathrm{P}<0.05\right)$. (B) Function of VEGF in the THP-1 cell culture supernatant was assessed using tube formation assay as described in the Materials and methods. Following incubation of the EA.hy 926 cells with each conditioned medium, tube formation was photographed under a microscope (x40 magnification). A representative image of 4 independent experiments is shown. (C) Tubes were counted and statistically analyzed using a Student's t-test ("P<0.05). 
altered in other cells through exosomes, several types of cells were treated with exosomes. Human monocytes were isolated from human blood. PBMCs were isolated from blood by Ficoll-Plaque using density-gradient centrifugation and monocytes were collected using a monocyte isolation kit. Exosomes were added to human monocytes for $16 \mathrm{~h}$ and COX-2 protein expression was detected by western blot analysis. As in the monocytic leukemia cell line, THP-1, the concentration of COX-2 increased in the human primary monocytes following treatment with exosomes from the celecoxib-treated 11-18 cell supernatant (Fig. 4A).

To examine whether exosomes from lung cancer cells transfer COX-2 to the same lung cancer type, exosomes from the 11-18 cells were added to the 11-18 cells. However, the concentration of COX-2 was not altered (data not shown).

Exosomes isolated from the celecoxib-treated 11-18 cell supernatant were added to Raji cells (a Burkitt's lymphoma B cell line), EA.hy926 (a human umbilical vein cell line) and HUVECs (a human primary umbilical vein endothelial cell line). The concentration of COX-2 was not higher in the Raji cells, but differed in the EA.hy926 cells and HUVECs (Fig. 4B).

The production of $\mathrm{PGE}_{2}$ and VEGF is increased by the transfer of COX-2 through exosomes. To measure the function of COX-2 transferred from exosomes, a $\mathrm{PGE}_{2}$ EIA assay was performed. The cell culture supernatant collected following treatment of the THP-1 cells with exosomes from celecoxibtreated 11-18 cells for $16 \mathrm{~h}$ revealed that $\mathrm{PGE}_{2}$ production increased following incubation with the exosomes (Fig. 5A). As $\mathrm{PGE}_{2}$ stimulates angiogenic VEGF production in monocytes (29), VEGF ELISA was performed using the supernatant of THP-1 cells treated with exosomes. The production of both $\mathrm{PGE}_{2}$ and VEGF was higher in the THP-1 cells treated with exosomes than in the controls (Fig. 5A).

Following incubation with exosomes from the celecoxibtreated lung cancer cells, conditioned medium of THP-1 was added to the EA.hy926 cells. In response to VEGF in medium, tube formation was observed in the EA.hy926 cells, as in HUVECs. The THP-1 cells incubated with exosomes from the celecoxib-treated 11-18 cells produced angiogenic factors, which triggered more tube formation in the EA.hy926 cells than in the control exosomes (Fig. 5B). Tube formation counts were measured and analyzed, as shown in Fig. 5C.

\section{Discussion}

Lung cancer has the highest cancer mortality rate worldwide. Efforts through surgery, radiotherapy and chemotherapy to improve lung cancer therapy have increased the survival rate; however, effective chemotherapeutic agents are still required. The abnormalities of EGFR, KRAS and anaplastic lymphoma kinase (ALK) genes are being targeted to lung cancer therapy. COX-2 is a possible target of lung cancer. Celecoxib, a selective COX-2 inhibitor, has binding pockets that interact with COX-2 and disrupt enzymatic activities. Actually, a high concentration of celecoxib $(>100 \mu \mathrm{M})$ effectively induced the death of lung cancer cells (data not shown). In addition, celecoxib also regulates COX-2 expression. According to other studies, COX-2 transcription is decreased by celecoxib in cells from gastric cancer, colon cancer and breast cancer (30-32). However, this study demonstrated that COX-2 expression was paradoxically increased following treatment with celecoxib in lung cancer cells. Of note, other COX-2 specific inhibitors (etoricoxib and rofecoxib) did not increase COX-2 expression, although a high concentration of sodium salicylate slightly increased COX-2 levels (data not shown). Ramer et al suggested the induction of COX-2 expression followed by the activation of PPAR $\gamma$ in lung cancer cells (20). However, we observed that PPAR $\gamma$ siRNA and GW9662 as a PPAR $\gamma$ antagonist did not regulate COX-2 expression in our experimental system (data not shown). It may be that the mechanism of COX-2 induction in lung cancer cells is so complex that it cannot be simply explained. The microarray analysis of celecoxib-treated lung cancer cells revealed that not only COX-2, but also numerous transcription factors were altered by celecoxib (data not shown). Of note, since celecoxib in exosomes may affect COX-2 expression in THP-1, the THP-1 cells were treated with celecoxib; however, there was no change in the levels of COX-2 (Fig. 3B). Although THP-1 is also a cancer cell line (such as A549, H460 and $11-18$ cells), even $50 \mu \mathrm{M}$ of celecoxib did not directly increase COX-2 expression. We hypothesized that this was due to the fact that THP-1 originates from monocytes and is associated with different cellular signaling pathways. To elucidate the mechanisms responsible for the paradoxical increase in COX-2 expression by celecoxib, further studies using numerous transcriptional controls of COX-2 are warranted.

Exosomes have recently been recognized as a system of delivery. As exosomes can transfer molecules to other cells, the study of exosomes has been carried out in various diseases $(23,25,26,28)$. This study demonstrated that exosomes transfer COX-2 from lung cancer cells to monocytes. Consequently, COX-2, which is delivered through exosomes, increases $\mathrm{PGE}_{2}$ and VEGF production. The mRNA level of COX-2 was not altered when the exosomes were added to the THP-1 cells (Fig. 3C), demonstrating that the increase in COX-2 expression in THP-1 cells was not due to transcriptional stimulation or transfer of COX-2 mRNA by exosomes. Accordingly, proteins of COX-2 in exosomes may have been directly transferred to the THP-1 cells. As shown in Fig. 4, the concentration of COX-2 was also somewhat elevated when the control exosomes were added to other cells. As untreated 11-18 cells constitutively express COX-2 (Fig. 1), their exosomes can contain COX-2 and transfer it to other cells.

Celecoxib is used as an anti-pain and anti-inflammatory drug and is considered a probable agent for the adjuvant therapy of COX-2-positive cancers. Cancer cells highly expressing COX-2 are believed to be a target of celecoxib. In this study, we found that the expression of COX-2 was increased by celecoxib in both COX-2-negative and -positive lung cancer cells. The intrinsic functions of the induced expression of COX-2 in lung cancer cells were not examined; however, we determined that great amounts of COX-2 were loaded into exosomes from lung cancer cells, where these could be delivered to adjacent or distant cells. Monocyte uptake of COX-2 via exosomes led to the increased production of $\mathrm{PGE}_{2}$ and VEGF, despite the presence of celecoxib. Thus, the anti-inflammatory effects of celecoxib may be diminished and may depend on the amount of exosome uptake and the effective concentration of celecoxib within lesions. In addition, after the administration of celecoxib ceases, previously secreted exosomes remain and can 
act on other cells. Additional research is required to explain the comprehensive effects on the whole body of the exosomal transport of COX-2.

Taken together, the findings of the present study demonstrate that celecoxib-induced COX-2 expression in lung cancer cells is transferred to other cells by exosomes. These results provide some indications that celecoxib modulates COX-2-positive cancer cells and affects the microenvironments, including inflammatory reactions.

\section{Acknowledgements}

This study was supported by the Basic Science Research Program through NRF funded by the Ministry of Education (NRF-2012R1A1A2006909, NRF-2015R1D1A1A01060152).

\section{References}

1. Hirsch FR and Lippman SM: Advances in the biology of lung cancer chemoprevention. J Clin Oncol 23: 3186-3197, 2005.

2. Keith RL: Lung cancer chemoprevention. Proc Am Thorac Soc 9: 52-56, 2012.

3. Dela Cruz CS, Tanoue LT and Matthay RA: Lung cancer: Epidemiology, etiology, and prevention. Clin Chest Med 32: 605-644, 2011 .

4. Sandler AB and Dubinett SM: COX-2 inhibition and lung cancer. Semin Oncol 31 (Suppl 7): 45-52, 2004.

5. Dy GK and Adjei AA: Novel targets for lung cancer therapy: Part I. J Clin Oncol 20: 2881-2894, 2002.

6. Chen G, Kronenberger P, Teugels E, Umelo IA and De Grève J: Targeting the epidermal growth factor receptor in non-small cell lung cancer cells: The effect of combining RNA interference with tyrosine kinase inhibitors or cetuximab. BMC Med 10: 28, 2012.

7. Cuneo KC, Nyati MK, Ray D and Lawrence TS: EGFR targeted therapies and radiation: Optimizing efficacy by appropriate drug scheduling and patient selection. Pharmacol Ther 154: 67-77, 2015.

8. Herbst RS, Heymach JV and Lippman SM: Lung cancer. N Engl J Med 359: 1367-1380, 2008.

9. Gasparini G, Longo R, Sarmiento R and Morabito A: Inhibitors of cyclo-oxygenase 2: A new class of anticancer agents? Lancet Oncol 4: 605-615, 2003.

10. Breyer MD, Harris RC and Matthew D: Cyclooxygenase 2 and the kidney. Curr Opin Nephrol Hypertens 10: 89-98, 2001.

11. Frungieri MB, Calandra RS, Mayerhofer A and Matzkin ME: Cyclooxygenase and prostaglandins in somatic cell populations of the testis. Reproduction 149: R169-R180, 2015.

12. Vosooghi M and Amini M: The discovery and development of cyclooxygenase-2 inhibitors as potential anticancer therapies. Expert Opin Drug Discov 9: 255-267, 2014.

13. Ghosh N, Chaki R, Mandal V and Mandal SC: COX-2 as a target for cancer chemotherapy. Pharmacol Rep 62: 233-244, 2010.
14. Rizzo MT: Cyclooxygenase-2 in oncogenesis. Clin Chim Acta 412: 671-687, 2011.

15. Grösch S, Maier TJ, Schiffmann S and Geisslinger G: Cyclooxygenase-2 (COX-2)-independent anticarcinogenic effects of selective COX-2 inhibitors. J Natl Cancer Inst 98: 736-747, 2006.

16. Liggett JL, Zhang X, Eling TE and Baek SJ: Anti-tumor activity of non-steroidal anti-inflammatory drugs: Cyclooxygenaseindependent targets. Cancer Lett 346: 217-224, 2014.

17. Kismet K, Akay MT, Abbasoglu O and Ercan A: Celecoxib: A potent cyclooxygenase-2 inhibitor in cancer prevention. Cancer Detect Prev 28: 127-142, 2004.

18. Wu T, Leng J, Han C and Demetris AJ: The cyclooxygenase-2 inhibitor celecoxib blocks phosphorylation of Akt and induces apoptosis in human cholangiocarcinoma cells. Mol Cancer Ther 3: 299-307, 2004.

19. Jendrossek V: Targeting apoptosis pathways by Celecoxib in cancer. Cancer Lett 332: 313-324, 2013.

20. Ramer R, Walther U, Borchert P, Laufer S, Linnebacher M and Hinz B: Induction but not inhibition of COX-2 confers human lung cancer cell apoptosis by celecoxib. J Lipid Res 54: 3116-3129, 2013.

21. Frydrychowicz M, Kolecka-Bednarczyk A, Madejczyk M, Yasar S and Dworacki G: Exosomes - structure, biogenesis and biological role in non-small-cell lung cancer. Scand J Immunol 81: 2-10, 2015.

22. Miller IV and Grunewald TG: Tumour-derived exosomes: Tiny envelopes for big stories. Biol Cell 107: 287-305, 2015.

23. Nazimek K, Bryniarski K, Santocki M and Ptak W: Exosomes as mediators of intercellular communication: Clinical implications. Pol Arch Med Wewn 125: 370-380, 2015.

24. Zhang X, Yuan X, Shi H, Wu L, Qian H and Xu W: Exosomes in cancer: Small particle, big player. J Hematol Oncol 8: 83, 2015.

25. Milane L, Singh A, Mattheolabakis G, Suresh M and Amiji MM: Exosome mediated communication within the tumor microenvironment. J Control Release 219: 278-294, 2015.

26. Hannafon BN and Ding WQ: Intercellular communication by exosome-derived microRNAs in cancer. Int J Mol Sci 14: 14240-14269, 2013.

27. Zhang J, Li S, Li L, Li M, Guo C, Yao J and Mi S: Exosome and exosomal microRNA: Trafficking, sorting, and function. Genomics Proteomics Bioinformatics 13: 17-24, 2015.

28. Roma-Rodrigues C, Fernandes AR and Baptista PV: Exosome in tumour microenvironment: Overview of the crosstalk between normal and cancer cells. Biomed Res Int 2014: 179486, 2014.

29. Höper MM, Voelkel NF, Bates TO, Allard JD, Horan M, Shepherd D and Tuder RM: Prostaglandins induce vascular endothelial growth factor in a human monocytic cell line and rat lungs via cAMP. Am J Respir Cell Mol Biol 17: 748-756, 1997.

30. Xiang HG, Xie X, Hu FQ, Xiao HB, Zhang WJ and Chen L: Cyclooxygenase-2 inhibition as a strategy for treating gastric adenocarcinoma. Oncol Rep 32: 1140-1148, 2014.

31. Fatima N, Yi M, Ajaz S, Stephens RM, Stauffer S, Greenwald P, Munroe DJ and Ali IU: Altered gene expression profiles define pathways in colorectal cancer cell lines affected by celecoxib. Cancer Epidemiol Biomarkers Prev 17: 3051-3061, 2008.

32. Dai ZJ, Ma XB, Kang HF, Gao J, Min WL, Guan HT, Diao Y, Lu WF and Wang XJ: Antitumor activity of the selective cyclooxygenase-2 inhibitor, celecoxib, on breast cancer in vitro and in vivo. Cancer Cell Int 12: 53, 2012. 